\title{
Balance de los Servicios de Información del Patrimonio Histórico 2001
}

\author{
Centro de Documentación del IAPH \\ Coordinación del texto: Ángela Blanco Muriel
}

Los servicios de información del Centro de Documentación del Instituto Andaluz del Patrimonio Histórico constituyen una serie de actividades encaminadas a suministrar información y/o documentación relativa al Patrimonio Histórico en general y con especial hincapié en los bienes culturales andaluces. Los servicios que suministra un organismo son los principales responsables de la imagen que proyecta éste al exterior. En consonancia con esta responsabilidad, su desarrollo debe ser medido y posteriormente analizado con el fin de lograr una evaluación integral que conlleve una propuesta de medidas efectivas para su mejora permanente. En este sentido, se evalúan anualmente los servicios que ofrece el Centro de Documentación del IAPH desde 1995, con objeto de analizar su evolución, investigar los posibles fallos y los logros obtenidos, detectar necesidades y vislumbrar posibles mejoras.

Hasta el momento estas evaluaciones anuales se han basado en analizar los datos estadísticos recabados por el personal encargado de suministrar los servicios. Para ello, se han utilizado diversos instrumentos de control (registros informatizados, formularios) que se han ido perfeccionando a medida que los análisis se iban haciendo más exhaustivos. A estos datos hay que añadir la observación e iniciativa del personal implicado en el desempeño de los servicios, que los han enriquecido aportando matices, comentarios y reflexiones. Se ha logrado así, realizar una evaluación interna o auto-evaluación continua que habría que completar con una evaluación externa de los usuarios de dichos servicios. Por el momento esta evaluación externa se efectúa de manera informal, por la propia iniciativa de los usuarios, que nos han remitido diversas cartas de felicitaciones, sugerencias y comentarios diversos. No obstante, está previsto que para finales del 2002 se comiencen a realizar encuestas formales para los usuarios de determinados servicios.

El informe de evaluación anual se ha ido convirtiendo en una tarea cada vez más precisa y exhaustiva en la que participa todo el personal del Centro de Documentación del IAPH involucrado en suministrar directamente los diversos servicios de información que están en funcionamiento. Aunque el informe resultante es muy amplio, queremos aquí resaltar los datos y las conclusiones más relevantes de cada servicio en el año 200।. [Datos recopilados en febrero 2002].

\section{El Servicio de Demandas Puntuales de Información}

Este servicio, que lleva funcionando desde finales de 1995, responde a las demandas de información planteadas por nuestros usuarios. Estas demandas son de muy diversa índole y generan un trabajo muy variado por parte de los documentalistas que las atienden: búsquedas bibliográficas, búsquedas legislativas, orientación general al usuario, búsquedas de información en bases de datos de bienes culturales, suministro de datos de referencia, etc. Actualmente es atendido en dos unidades: el Servicio de Información del Centro de Documentación del IAPH (SI) y la Unidad de Información de la Dirección General de Bienes Culturales (UI-DGBC).
Su desarrollo es objeto de un análisis pormenorizado, labor en la que se sigue avanzando cada año para conseguir una evaluación con la mayor profundidad posible. Ello ha conllevado recientemente una selección de nuevos indicadores (por ej. nivel de pertinencia de la petición, tipología de la temática, tiempo de respuesta, formatos de envío) que han sido incorporados a la Base de Datos de Registro de Peticiones de Información, fuente de la que se extraen las cifras estadísticas anuales. En concreto durante el 200 I se destacan los siguientes datos:

El volumen anual de la demanda se mantiene estable. Hay que señalar que en los últimos tres años las cifras son muy similares, tras el espectacular crecimiento acaecido en los primeros años de funcionamiento (Gráfico I). Durante el año 200 I se reciben y contestan en el SI y la UI-DGBC un total de 1.057 peticiones, siendo esta cifra sólo superada ligeramente en 1.999, que obtuvo 1.102 demandas. Hay que tener en cuenta que en dicho año también estaba en funcionamiento otra Unidad, la de la Delegación de Cultura en Sevilla, proyecto piloto ya finalizado.

El número de peticiones sigue siendo considerablemente mayor que el de usuarios (605) (Gráfico 2). Como ya hemos dicho en anteriores balances, este servicio tiene usuarios que se pueden definir como usuarios-clientes, debido a la frecuencia con que lo utilizan.

Gráf. 1. Volumen comparativo de demandas de información 1995-2001

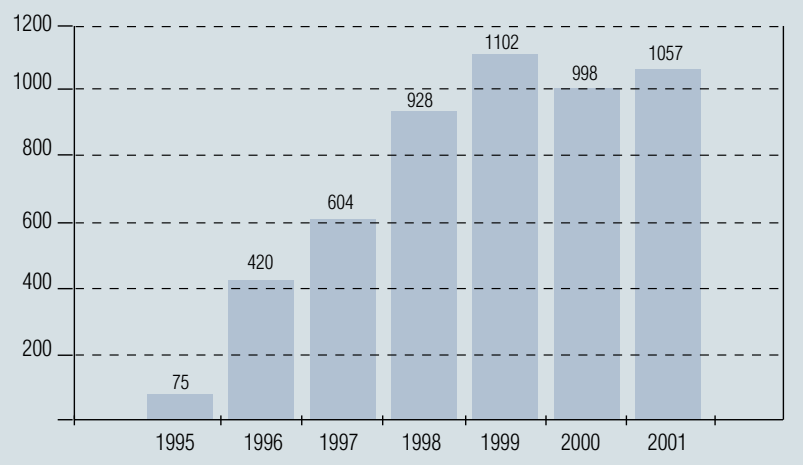


Gráf. 2. Volumen comparativo Peticiones-Usuarios 2001

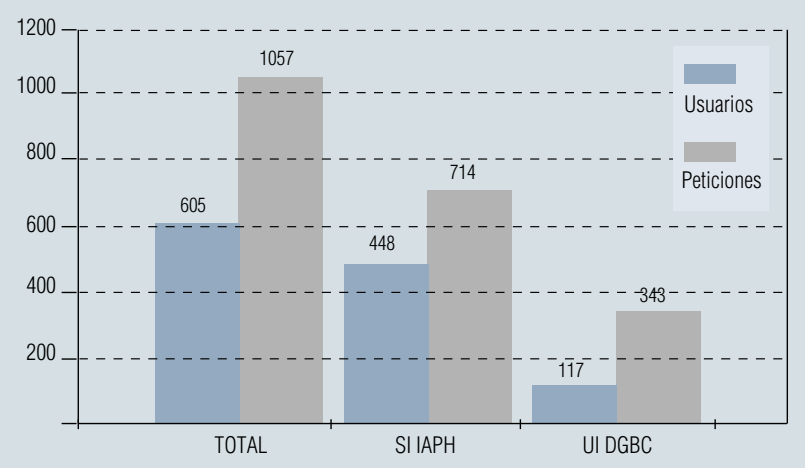

Gráf. 3. Tipología usuarios externos SI-IAPH 2001

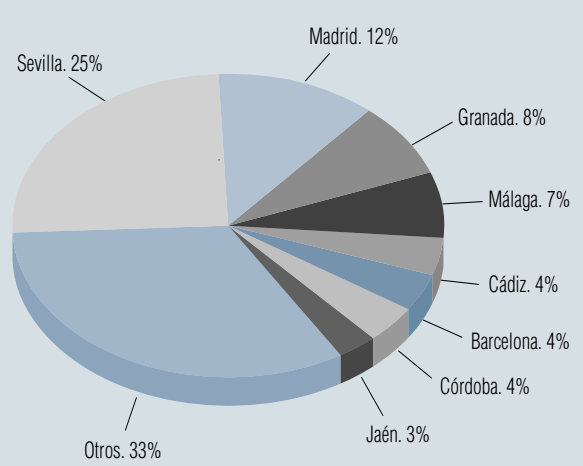

Aparte de estos datos generales, siempre hemos considerado conveniente abordar el estudio de las demandas de cada unidad por separado, ya que presentan peculiaridades que podrían quedar enmascaradas en un análisis global.

\section{a. Demandas del Servicio de Información del Centro de Documentación del IAPH (SI)}

En cuanto al volumen anual específico del SI, el número de peticiones recibidas ha sido durante el 200 I de $7 \mid 4$. El volumen total es, así, ligeramente superior al de otros años, en concreto 67 más que el año anterior (el año 2000 tuvo un total de 647 peticiones y 1999, 61 I). En este análisis sectorial se comprueba que el SI no ha dejado de incrementar anualmente el número de peticiones desde sus inicios, aunque ya de una manera más moderada.

De estas peticiones que se reciben, se ha detectado que una parte (en concreto este año el 7,5\%), no son pertinentes por diversos motivos: la temática es totalmente ajena a nuestras competencias, se demandan servicios que no están en marcha o no se formulan adecuadamente. Aun así, hemos intentado en la mayoría de los casos redirigir a los usuarios a los organismos adecuados para contestarlas. Por otro lado, consideramos que el nivel de respuesta de las peticiones pertinentes ha sido bastante alto, un $98 \%$. Nos queda por saber si las respuestas han sido consideradas adecuadas por nuestros usuarios, datos que esperamos empezar a recabar para las peticiones del último trimestre del 2002 y en adelante, a través de una encuesta de evaluación dirigida a averiguar su nivel de satisfacción.

En cuanto a la tipología de nuestros usuarios en el 200I, se diferencian en principio dos grandes grupos: internos y externos. Hay que resaltar que en el SI la gran mayoría son externos, en total hay 664 peticiones frente a las 50 internas, las cuales representan un $7 \%$ del total. Aunque siempre han sido más numerosos los usuarios externos, ya que este servicio en concreto está abierto a cualquier tipo de usuarios, este año los internos han experimentado una bajada significativa ya que venían suponiendo aproximadamente el $20 \%$ de las demandas anuales. Creemos que esta bajada es debida en parte a que el personal del IAPH cuenta a partir de este año con varios puestos de libre consulta en la Sala de Información para acceder a los recursos informativos del Centro.

En cuanto a los externos, aunque hay gran variedad de tipología de usuarios (Gráfico 3), nos encontramos con cuatro grandes grupos que representan el $75 \%$ de las peticiones. El más numeroso ha sido este año, con 183 peticiones, el grupo de empresas privadas y profesionales del Patrimonio Histórico (arquitectos, restauradores, etc.) que demandan información para su desarrollo profesional. Lo sigue el grupo de investigadores, con 126 demandas. Tras él y con cifras muy similares, 124 peticiones, nos encontramos con un grupo bastante heterogéneo que hemos deno- minado como "público en general" y en el que se han incluido grupos no identificados $y$ particulares. En cuarto lugar, 104 demandas, el grupo de estudiantes, en su gran mayoría universitarios, que suelen requerir la información para realizar trabajos académicos. En cuanto al resto de grupos, ya con cifras bastante más bajas destaca la administración autonómica con 45 peticiones, seguida de la administración local con 4I.

Se considera de gran interés para la buena marcha del Servicio el estudio tanto de nuestros usuarios reales como potenciales, y en este sentido venimos realizando periódicamente Estudios de Usuarios desde 1998. Recientemente se ha elaborado una encuesta sobre necesidades de información que ha sido cumplimentada por los usuarios internos, actualmente está en fase de estudio, y posteriormente será adaptada a los externos. Con las conclusiones que se extraigan tanto de estas encuestas como de los datos estadísticos anuales sobre nuestros usuarios reales, esperamos determinar los usos y necesidades de colectivos específicos de usuarios, para proceder al establecimiento de las propuestas correctoras más adecuadas para nuestros servicios. Todo ello con el objeto de adaptarnos lo máximo posible a las necesidades de nuestros usuarios.

Por lo que respecta a la procedencia geográfica, el mayor número de peticiones proviene lógicamente de Andalucía, alcanzando este año el 80\% (572 peticiones). Las peticiones de otras Comunidades Autónomas constituyen el $13 \%$, y las del extranjero casi un $6 \%$. Hay que 
resaltar que han subido ambas los porcentajes ligeramente respecto a otros años.

De las peticiones de Andalucía, el estudio por provincias nos indica que la gran mayoría son de Sevilla, en concreto el 56\%. Hay que destacar que esta proporción ha bajado significativamente en los últimos años, ya que en el 2000 representaba el 67\%, en 1999 el $72 \%$ y en 1998 el $78 \%$. Por otra parte, el aumento durante el año de estudio de las peticiones procedentes de otras provincias ha significado un logro para el SI, ya que se había planteado como uno de sus objetivos primordiales el potenciar el servicio en el resto de la Comunidad Andaluza. Durante el 2001 se recibieron peticiones de todas las provincias andaluzas, siendo tras Sevilla, Granada y Málaga las que más demandas han cursado (58 y 54 respectivamente) y Almería la que menos con 19.

En cuanto a la temática demandada por los usuarios, ha sido muy variada y además es habitual que una misma petición abarque varias áreas temáticas (patrimonio arqueológico, arquitectónico, mueble, etc.). No obstante se ha clasificado por grandes tipologías (Gráfico 4), constatándose tres grupos principales con cifras similares: Arquitectura, Arqueología y Patrimonio Histórico en general. Este último grupo correspondería a peticiones en que se demanda todo el Patrimonio Histórico de cualquier tipología, acotado bien geográficamente o bien por cualquier otro factor (época, estilo, etc.). Tras estos tres, hemos destacado otros nueve como el Patrimonio Artístico Mueble, Historia del Arte o Conservación.

En lo que respecta a la adecuación de los recursos internos a dicha demanda, es decir las bases de datos creadas o desarrolladas por el Centro de Documentación del IAPH, la proporción de peticiones que se resuelven en parte $\circ$ en su totalidad con estas fuentes de información es de un 76\% (Gráfico 5). Porcentaje que se ha ido incrementado en los últimos años (en 1997 era de un 67\%). Ello indica que cada vez más las peticiones se adecuan a nuestras fuentes y viceversa. Por tanto la gran mayoría de las peticiones se resuelve con productos propios (bases de datos de Patrimonio Arqueológico, Arquitectónico, Etnológico, Mueble, Biblos, Conjuntos Históricos y Catálogo de la Biblioteca). El otro 24\% de las demandas se responde en gran parte con las fuentes de información externas disponibles en el Centro: CD-Rom, Internet, directorios, etc.

Por último, en cuanto a las modalidades de recepción y envío de las peticiones, hay que destacar el gran incremento del correo electrónico como medio tanto de llegada de las peticiones al Centro como de salida de la información del mismo. En el 2001 se convierte así en el medio más usado con 302 peticiones recibidas por correo electrónico y 289 respuestas remitidas. En el 2000, aunque había aumentado su uso espectacularmente, era superado ligeramente como medio de recepción por el teléfono y como medio de salida por el correo ordinario. En lo que respecta a la remisión de información, el correo electrónico ha supuesto para el Servicio una agilización de los trámites de envío y ha facilitado el tratamiento posterior de la información por parte de los usuarios. Como medio de recepción ha logrado por un lado, un mayor incremento de las peticiones, pero por otro, al ser de una mayor libertad de acceso ha aumentado considerablemente el número de demandas no pertinentes, que casi exclusivamente llegan por esta vía. Tras el correo electrónico, el teléfono es el segundo medio de entrada de peticiones (128), lo siguen el modo presencial (90), correo ordinario (62) y fax (58). En cuanto al modo de envío de la información a los usuarios el orden varia: correo ordinario (188), modo presencial (75), teléfono (52) y fax (26).

\section{b. Demandas de la Unidad de Información de la Dirección General de Bienes Cultura- les (UI-DGBC)}

Esta unidad atiende todas las peticiones de información procedentes de la DGBC así como las de usuarios externos que se dirigen a ella.

El volumen de peticiones resueltas por la UIDGBC en el año 200I ha sido de un total de 343 (Gráfico 2). La media mensual resultante es de 28 peticiones/mes. En cuanto a la evolución por meses, octubre fue el mes que

\section{Gráf. 4. Ámbito temático de la demanda SI-IAPH 2001}

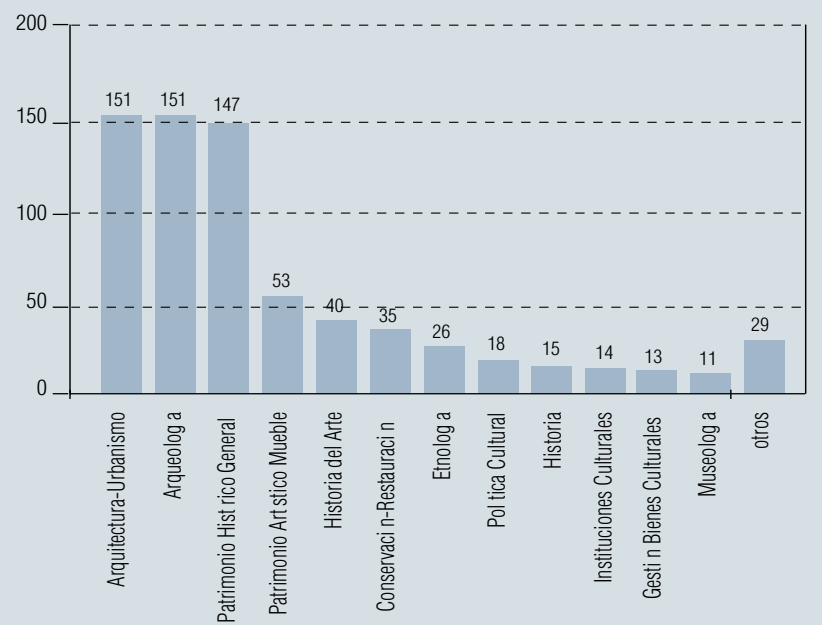

Gráf. 5. Utilización de las bases de datos internas SI-IAPH 2001

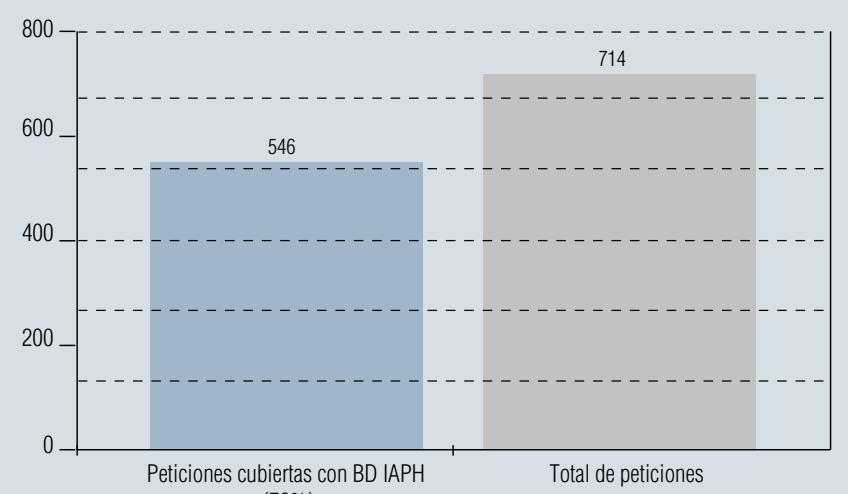

$(76 \%)$ 
contó con mayor número de peticiones, con 43 demandas y agosto el mes que tuvo una demanda menor con 2 peticiones.

El carácter básicamente interno de la UI condiciona, lógicamente, la tipología de usuarios, siendo el número de éstos muy inferior al de demandas de información. En este sentido, nos encontramos con un tipo de usuario al que podemos considerar de carácter habitual, ya que ha habido una alta proporción que ha usado los servicios de la UI en varias ocasiones. En el año 2001 las peticiones fueron realizadas por un total de 117 usuarios. Si analizamos el Origen de las peticiones (Gráfico 6) nos encontramos con tres grandes grupos:

- Peticiones procedentes de la DGBC.

- Peticiones procedentes del Centro de Documentación del IAPH.

- Peticiones externas.

La mayor parte corresponden a la DGBC, seguida de usuarios externos, con 185 y 108 peticiones respectivamente; el IAPH realizó en este período un total de 50 consultas.

Los Servicios de la DGBC que más han utilizado la UI son: la Oficina del Plan con 94 peticiones y el Servicio de Protección con 75 peticiones; le siguen el Servicio de Conservación con 12 peticiones y el Servicio de Investigación y Difusión con 4 peticiones.

Las demandas externas, que este año han tenido un significativo crecimiento con un total de 108 peticiones, tienen la siguiente tipología de usuarios: el mayor número de peticiones ha sido para uso empresarial (38), seguidas de las de uso institucional (37), estando en último lugar las peticiones realizadas para usos particulares (33).

Algunas de estas peticiones proceden de otras provincias andaluzas y del resto de España, en concreto, de otras comunidades ha habido 24 demandas de información y del resto de las provincias de Andalucía el total ha sido de 22. Pero, como cabría esperar, por las mismas condiciones de la UI, el resultado tiene un balance local en lo que a procedencia geográfica se refiere.

La temática de las peticiones se centra, principalmente, en actividades relacionadas con la gestión de los bienes culturales, ya sean datos referentes a la protección de éstos, como intervenciones o inversiones realizadas en un área geográfica o en un bien concreto. Un análisis más pormenorizado revela que la mayor parte de peticiones se resuelven con las fuentes de información internas, y hay que resaltar que para la resolución de muchas de ellas se han utilizado las fuentes existentes en la DGBC.

\section{El Servicio de Información de Boletines Oficiales}

Este es un servicio interno que suministra el Servicio de Información del IAPH. Consiste por una parte, en la distribución semanal de dossieres de sumarios BOE-BOJA, desde
1999 en formato electrónico a través de la red interna. $Y$ por otro, en atender las peticiones de reproducción de disposiciones legales, además de numerosos préstamos de boletines oficiales. Durante el 2001 ha cumplido con estos objetivos, enviando un dossier semanal a una lista de distribución de usuarios internos seleccionados y atendiendo a todas las peticiones de reproducción y préstamo de boletines habidas.

\section{Los Servicios de Información del Fondo Bibliográfico}

Facilitan el acceso y recuperación de la información contenida en el catálogo del fondo bibliográfico de la Biblioteca del IAPH y son los siguientes (Gráfico 7):

Servicio de Préstamo. Por el momento sólo está establecido para usuarios internos, aunque se suministra de forma puntual y en un número considerablemente menor a otros usuarios como colaboradores y personal de la Consejería de Cultura, así como personas expresamente autorizadas. Además, desde el año 2000 se ha hecho extensible a los alumnos de los Master impartidos por el Instituto Andaluz del Patrimonio Histórico, dadas las reiteradas peticiones por parte de los mismos al personal de esta Biblioteca, y considerando que se desarroIlan en las dependencias del IAPH.

Este servicio está sujeto a normas que regulan tanto su duración como el número de ejemplares a prestar, dependiendo de la tipología de los usuarios y de los fondos. El balan-

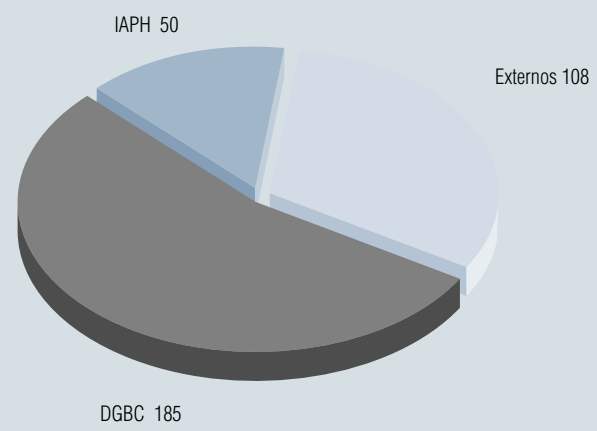

DGBC 185

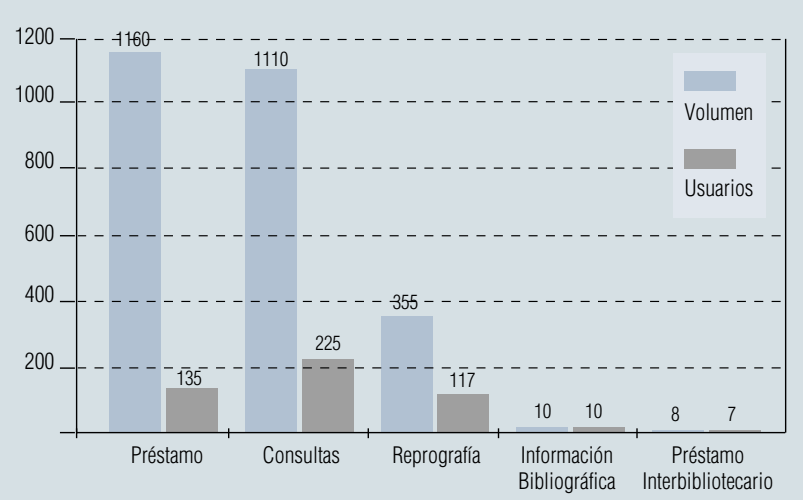



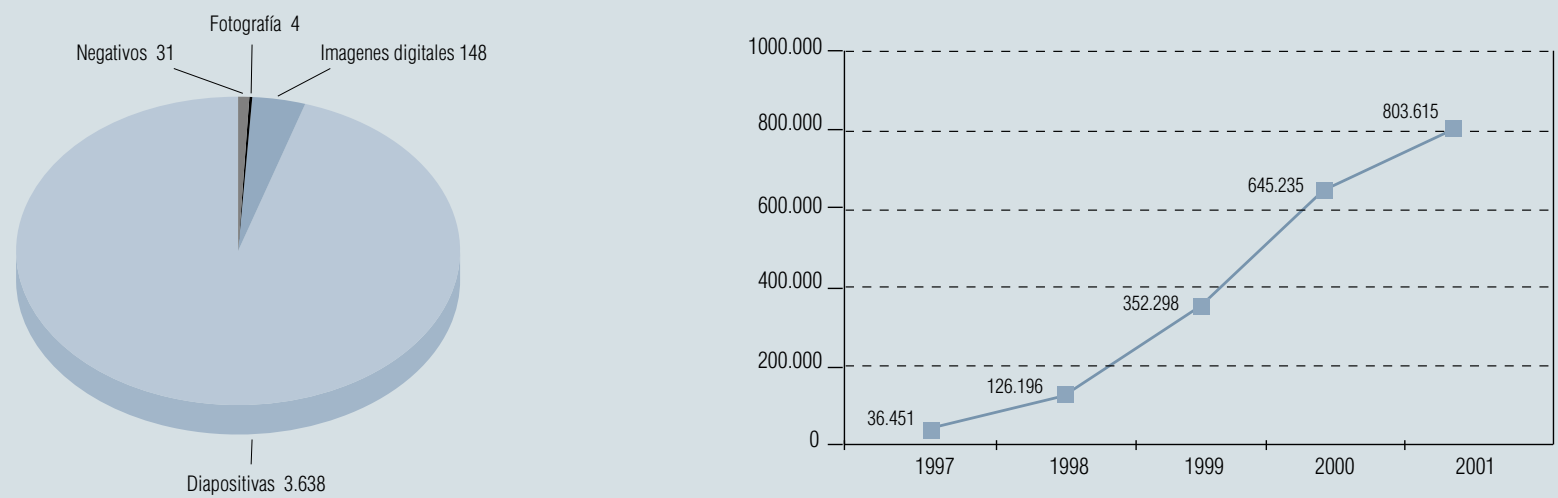

ce del año 2001 ha sido de 1.160 préstamos a 136 usuarios ( 105 internos y 31 externos), habiendo experimentado un ascenso tanto de préstamos como de usuarios respecto al año 2000 en que se realizaron 884 préstamos a II 4 usuarios.

Servicio de Consulta. Servicio de libre acceso, que dispone de una Sala de Consulta con 20 puestos de lectura en los que el lector puede consultar directamente los fondos bibliográficos que se encuentran ordenados bajo criterios temáticos. A lo largo del pasado año tuvimos 225 usuarios externos con un total de 1.110 consultas de nuestros fondos, con lo cual también ha habido un ascenso significativo respecto al 2000 en que hubo 830 consultas de 1 II usuarios.

Servicio de Reprografía. Servicio ampliado a usuarios externos desde 1.999. Las peticiones de fotocopias se solicitan a través de los impresos disponibles en la Sala de Consulta y se realizan en la fotocopiadora de uso público destinada a tal efecto situada en el Edificio A de las dependencias del IAPH mediante autoservicio. Durante el 200 I se han realizado 355 solicitudes de reproducción por parte de 117 usuarios externos.

Servicio de Información Bibliográfica. Consiste en la búsqueda de referencias bibliográficas de los documentos que el usuario precisa y de su identificación y localización. Responde a dos tipos de demandas: documentos concretos cuyos datos se conocen o información sobre un tema determinado. Este servicio se ha suministrado en 10 ocasiones al mismo número de usuarios. Hay que tener en cuenta que desde finales de 1998 se ha puesto en marcha el OPAC de libre acceso en la Sala de Consulta que permite el acceso y obtención directa de información del catálogo informatizado de la Biblioteca por parte del usuario, sin necesidad de la mediación del personal de la Biblioteca.

Servicio de Préstamo Interbibliotecario. Encaminado a facilitar el acceso a documentos no contenidos en el catálogo de la Biblioteca del IAPH. Por el momento se suministra de forma puntual a los usuarios internos; así se han atendido 8 peticiones de 7 usuarios en el $200 \mathrm{I}$. El personal de la Biblioteca está trabajando en el establecimiento sistemático de las normas e impresos necesarios para su implantación.

Elaboración de Boletines. Constituyen una serie de productos de alerta informativa destinados a la puesta al día de los usuarios en las novedades de interés de nuestros fondos bibliográficos. El Boletín de Novedades, se realiza con carácter trimestral, e informa de las novedades recibidas durante ese período de tiempo en la Biblioteca y presentadas bajo un orden temático. A lo largo del 2001 se distribuyeron a todos los Centros del IAPH los correspondientes a los trimestres enero-marzo, abril-junio y julio-septiembre. Se realiza últimamente su distribución en formato electrónico a través de la red interna y está prevista próximamente su distribución externa. La Selección Bibliográfica, también se elabora trimestralmente, en ella se destacan los títulos que se consideran de mayor interés y tiene como objeto su difusión a través del Boletín PH.

\section{Servicios de Información del Fondo Gráfico}

Desde el año 1999, en que se presentó por primera vez el balance de los servicios del Fondo Gráfico, se ha seguido trabajando en al mejora cuantitativa y cualitativa de la gestión del mismo. En cuanto al volumen, si comparamos las cifras totales de 200l, con las del año anterior, se aprecia un notable incremento.

\begin{tabular}{lrr}
\hline & Año 2000 & Año 2001 \\
\hline Diapositivas & 25.411 & 30.100 \\
\hline Fotografías & 4.274 & 4.300 \\
\hline Negativos & 14.441 & 17.520 \\
\hline I. digitales & 8.062 & 12.910 \\
\hline Totales & 52.188 & 64.830 \\
\hline
\end{tabular}

Vemos que se han puesto al servicio del usuario casi 13.000 nuevos registros. Además, el tratamiento documental también ha experimentado un avance muy significativo, al contar con una nueva versión de la base de datos gráfica que permite un mejor análisis descriptivo del documento gráfico; esta aplicación informática, útil y bien estructurada necesita ser implementada con un sistema de búsqueda, edición y listados de salida que permitan manejar adecuadamente los 64.830 registros. Así mismo resulta imprescindible contar con un módulo de gestión eficaz, en el que seguimos trabajando actualmente para poder atender las peticiones de los usuarios en sus demandas de información gráfica de manera más efectiva.

Los servicios prestados por el Fondo Gráfico, en el periodo 200 I son los siguientes: 
Servicio de Préstamo. En cuanto al volumen (Gráfico 8), el número total de peticiones es algo menor que el año anterior, pero en cambio ha aumentado el número de registros en cada petición, lo que da idea de la importancia que la imagen tiene en los trabajos realizados en el IAPH sobre todo en su labor de formación y difusión: cursos, conferencias, publicaciones, elaboración de Cd-Rom.

Tipología: las diapositivas siguen siendo hoy el formato más solicitado con diferencia del resto de tipologías, del mismo modo se observa el incremento de solicitudes en formato digital. De 57 registros solicitados el año 2000, se ha pasado a 148 registros, un aumento considerable, aunque lejano todavía a las casi 4.000 diapositivas. En el resto de las tipologías, negativos y positivos, sí vemos claramente la falta de demanda de los usuarios para su utilización.

El origen de estas peticiones sigue siendo mayoritariamente interno (69\%), ya que sólo de forma ocasional y con la autorización correspondiente se atienden las peticiones de usuarios externos (31\%). En cuanto a las peticiones internas según su origen, un gran bloque procede del Centro de Documentación y en menor medida del Centro de Intervención, y del Dpto. de Formación y Comunicación.

Por otro lado, hay un dato destacable y es el inicio de prestación de dos nuevos servicios, éstos son:

Gráf. 10. Bloques temáticos más visitados de la web del IAPH 2000

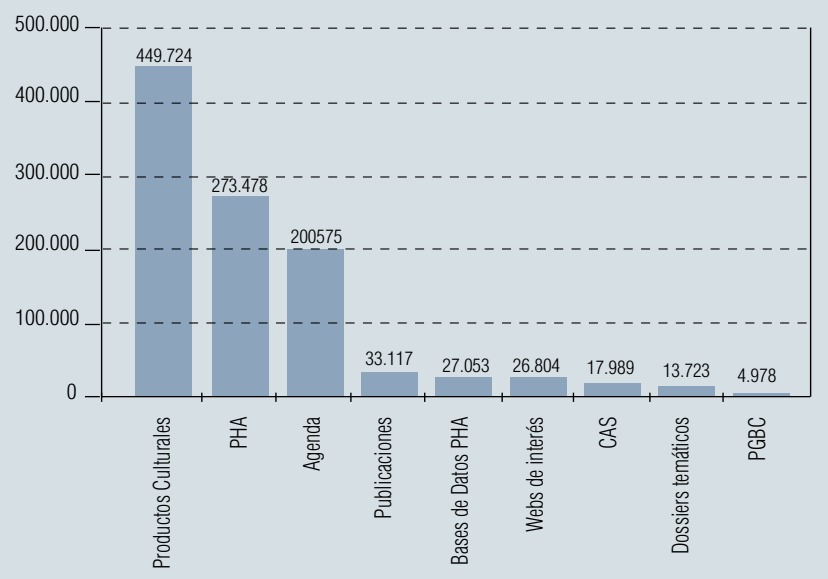

Servicio de referencia. Responde a la demanda de localización de colecciones de material gráfico de otros centros o instituciones, con 5 solicitudes todas ellas internas.

Servicio de consulta. Con 8 solicitudes, también de usuarios internos, demandando información gráfica de los bienes culturales de Andalucía existentes en nuestros fondos.

\section{Servidor Web del IAPH}

El Servidor Web del IAPH ha ido incrementando de forma significativa desde su implantación el número de accesos al mismo, pasando de unos 36.45 I en 1997, fecha en que se puso en servicio, hasta los 803.615 accesos del año 2001 (Gráfico 9). Durante este último año, cabe destacar que el mes de septiembre ha sido el de más afluencia de visitas con un total de 79.366, frente a las 48.253 del mes de enero. Este sustancial incremento de accesos viene dado por la incorporación al Servidor Web de información especializada en patrimonio, como son los Productos Culturales (Velázquez y Sevilla, Docomomo, Clausuras de Cádiz, etc.), con 449.724 accesos y acceso a Bienes Culturales andaluces en el apartado PHA con 273.478 consultas. Otros de servicios útiles para los usuarios son la Agenda de Cursos con posibilidad de inscripción a los mismos, con 200.575 accesos, o la opción de suscribirse al Boletín PH, dentro de la sección dedicada a las Publicaciones, con 33.117 accesos. Asimismo, son muy visitados los
Webs de interés (directorio de recursos externos), con un total de 26.804 accesos en el 200। (Gráfico I0).

Es también significativa la importancia de la incorporación de las bases de datos on line, como es el caso de la Base de Datos de Patrimonio Inmueble de Andalucía, que durante los tres últimos meses del 2001 obtuvo un total de 10.955 accesos. Ello ha supuesto la Consulta Dinámica en el Servidor Web del IAPH las bases de datos internas que se desarrollan en el Centro de Documentación, que se inició en 1999 con la base de datos de Arqueología (Arqueos), ampliándose en el 200 I con la aplicación de Patrimonio Inmueble que incluye las caracterizaciones de Patrimonio Arquitectónico, Arqueológico y Etnológico. El Servicio de Consulta de las Bases de Datos a través de Internet pretende, facilitar el acceso directo de los usuarios a las bases de datos internas, a través de las redes telemáticas, siendo sus usuarios de procedencia diversa $y$ amplia.

En definitiva, la incorporación de una información interactiva y de servicios útiles y necesarios, han incrementado el tráfico en la Página Web del IAPH, una sede que cuenta con alrededor de 3.500 páginas y unas 2.300 imágenes y con un total de 2.384 enlaces externos. Asimismo, el IAPH es visible desde el exterior en al menos, unas 250 sedes web, siendo España el país en el que se encuentra el mayor número de accesos, 1.468.442, frente a los $585.447 \mathrm{del}$ año 2000, así como Estados Unidos (I54.287), México (34.66I), Argentina (28.383), Italia (17.961), Portugal (10.770) y Francia ( 10.366$)$, siendo el incremento en estos países más equilibrado respecto al año anterior. La permanencia de la sede web durante cinco años y la mayor cualificación de sus contenidos hace que cada año se incrementen sus accesos de forma proporcional. Por ello, es necesario desarrollar contenidos novedosos y útiles al usuario interesado en el patrimonio histórico, así como facilitar el acceso directo a nuestros productos y servicios de forma ágil y rápida, proporcionando también la utilización de herramientas de búsqueda y el conocimiento de otros recursos externos relacionados con la materia en el ámbito nacional e internacional. 


\section{Proyecto piloto del Servicio de Acceso Directo}

Permite la consulta de las bases de datos internas e Internet a los usuarios internos y excepcionalmente a usuarios externos (apoyo a usuarios de la Biblioteca u otros servicios), mediante la creación de puestos de libre consulta en la Sala de Información desde el año 2000. Actualmente cuenta con cuatro puestos y el apoyo del personal del SI. Se facilita la búsqueda directa por los usuarios, así como la visualización, impresión y/o archivo de los resultados obtenidos, teniendo previsto iniciar una línea encaminada a la formación de usuarios. Este avance a favor de la consulta directa de los usuarios ha sido altamente positivo y se espera una apertura del servicio al resto de usuarios. Para su implantación a usuarios externos se prevé la elaboración y difusión de una Normativa Básica de Funcionamiento del Servicio, así como información explicativa como las instrucciones de consulta del/los módulo/s de consulta de las bases de datos; además del incremento de infraestructura técnica.

\section{Perspectivas de futuro}

La normalización y homogeneización de todos los servicios existentes son actualmente objetivos prioritarios en los que se está trabajando. Se pretende a corto plazo que cada servicio cuente con herramientas similares (e incluso en ciertos casos comunes) de gestión, control y evaluación. Además, la coordinación y cooperación que siempre ha existido entre ellos se pretende plasmar en una normativa básica de uso interno.

El Centro de Documentación del IAPH prevé avanzar paulatinamente en la implantación de nuevos servicios de acuerdo con las expectativas de nuestros usuarios y con los avances tecnológicos. También está prevista la posibilidad de abrir ciertos servicios que hasta el momento han sido de uso exclusivamente interno a los usuarios externos.

Paralelamente, seguiremos profundizando en el análisis de todos ellos para lograr aumentar su calidad. Además de las líneas concretas de mejora que ya se han comentado en cada servicio, en general se estudia el establecimiento de unos parámetros de calidad y su control permanente. Por otro lado, la consecución de una relación fluida con los usuarios de los mismos, que potencie la calidad y la retroalimentación del sistema, se considera fundamental.

Otra línea permanente de trabajo en el área la conforman las labores de difusión y divulgación tanto de los servicios, como del Centro de Documentación en general. Como novedades para el último trimestre del 2002-primer trimestre del 2003, hay que apuntar la edición de folletos de instrucciones de uso de determinados servicios y la reedición del tríptico informativo general.

En resumen, la consolidación de los servicios actuales, la diversificación y creación de nuevos servicios en consonancia con las necesidades de los usuarios y la obtención del máximo nivel de calidad en su prestación, se constituyen en estos momentos en los objetivos generales de los servicios de información del IAPH.

\section{Novedades del fondo gráfico del IAPH}

E| Fondo Gráfico del Instituto Andaluz del Patrimonio Histórico está compuesto por las imágenes procedentes de los proyectos de los Centros de Intervención, Documentación y Formación así como de la captación de imágenes procedentes de otros archivos (MAS, Ruiz Vernacci, Moreno y fotógrafos profesionales) y de instituciones públicas: Dirección General de Bienes Culturales y Universidad, entre otras. En total cuenta con aproximadamente 70.000 imágenes en distintos soportes: negativos (| 5.0|4), positivos (4.239), diapositivas (34.399) e imágenes digitales (13.339).

Estos documentos gráficos, que son en buena parte resultado final y fedatario de investigaciones y proyectos desarrollados por la institución, se encuentran recogidos en la base de datos Gráfica, diseñada para resolver las necesidades que plantea el uso de las imágenes como base o apoyo de estudios o trabajos de muy diversa índole. La descripción del documento gráfico está basada en la Norma Internacional General de Descripción Archivística (ISAD-G). Los elementos de descripción están estructurados en módulos que recogen la información específica del documento gráfico al que acompañan.

En cuanto al uso de las imágenes, en la actualidad es restringido al personal interno y ocasionalmente y con la autorización correspondiente se atienden las peticiones de usuarios externos. No obstante el fondo gráfico sigue trabajando en la implantación de los servicios de información.

A partir de ahora, las novedades del Fondo Gráfico del IAPH estarán presentes periódicamente en PH. La aparición de este boletín de adquisiciones del Fondo Gráfico es un paso más en la consolidación de la conservación y gestión del patrimonio documental fotográfico; con él pretendemos dar a conocer las adquisiciones e ingresos de conjuntos documentales que se han ido incorporando al mismo, ya sea como consecuencia de actividades o como adquisiciones directas del Fondo. De este modo queremos acercar al usuario la información gráfica más reciente. En él encontramos los datos más significativos de la ficha catalo- gráfica, que informan sobre: contenido, características físicas y disponibilidad de uso. Teniendo muy presente que nuestro objetivo primordial es la prestación de un servicio, ágil, útil y accesible.

Por lo que respecta a la presentación de sus datos de catalogación en esta publicación, se ha optado por una ficha-resumen, que agrupa todas las imágenes que pertenecen a un mismo inmueble. En la base de datos gráfica cada inmueble tiene una cantidad variable de imágenes con una descripción individualizada.

Las siguientes imágenes del IAPH han sido catalogadas por el fondo gráfico durante el primer semestre del año 2002 y proceden de adquisiciones a fotógrafos, tras la intervención en el patrimonio inmueble; otros documentos gráficos han sido realizados con el fin de inventariar los bienes muebles de la Iglesia Católica. En cuanto a su origen, pertenecen a Cádiz capital y a Sevilla capital y provincia. 